\title{
Stereospecific Regulation of Tyrosine Hydroxylase and Proenkephalin Genes by Short-Chain Fatty Acids in Rat PC12 Cells
}

\author{
PRADEEP MALLY, RAVI MISHRA, SWATI GANDHI, MANUEL H. DECASTRO, \\ BISTRA B. NANKOVA, AND EDMUND F. LAGAMMA \\ The Regional Neonatal Center, Westchester Medical Center, New York Medical College, Valhalla, New \\ York 10595, U.S.A.
}

\begin{abstract}
Circulating short-chain fatty acids (SCFAs) are primarily derived from bacterial fermentation of carbohydrates in the colon where they function as physiologic modulators of epithelial cell maturation. Butyrate has been shown to induce tyrosine hydroxylase, the rate-limiting enzyme of catecholamine synthesis, and enkephalin neuropeptide gene transcription, suggesting a role in perinatal sympathoadrenal stress-adaptation. We sought to determine whether there were SCFA structural requirements for this effect. Nine biologically relevant SCFAs and butyrate derivatives were tested in an in vitro model (PC12, rat pheochromocytoma cells) for their ability to regulate neurotransmitter-related gene expression. Our results revealed that among all the studied SCFAs, only propionate and butyrate increased tyrosine hydroxylase and proenkephalin mRNA levels. The functional activity was selective to the carbon atom chain length and associated with the presence of an ethyl moiety in the carbon atom backbone chain. Modifications or absence of this domain affected the gene induction response, suggesting a receptor-mediated mechanism(s). Moreover, propionate, butyrate, and the drug 4-phenylbutyrate were each shown to regulate transmitter genes via at least three independent mechanisms: histone hyperacetylation, cAMP signaling, or peroxisome proliferator-activated receptor gamma-mediated pathways. Thus, the biologic impact of SCFAs on catecholaminergic and opioid systems depend on the activation of SCFA-specific, dose-specific, and gene-specific molecu-
\end{abstract}

\section{ABSTRACT}

lar mechanisms. We speculate that 1) circulating levels of SCFAs may influence sympathoadrenal transmitter biosynthesis and hence whole animal stress-adaptive responsiveness after birth, and 2) the adverse effects of antibiotics on delayed acquisition of postnatal gut flora may affect this apparent evolutionary advantage of gut colonization. (Pediatr Res 55: 847-854, 2004)

$\quad$ Abbreviations
ppEnk, preproenkephalin
TH, tyrosine hydroxylase (EC 1.14.16.2)
PC12, rat pheochromocytoma
SCFA, short-chain fatty acids
SB, sodium butyrate
PKA, protein kinase A
PPAR, peroxisome proliferator-activated receptor
RT-PCR, reverse transcriptase-PCR
HDAC, histone deacetylase
TSA, trichostatin A
4-PB, phenylbutyrate
2-HB, 2-hydroxybutyrate
3-HB, 3-hydroxybutyrate
RXR, retinoid X receptor
PPRE, peroxisone proliferator response element
PMSF, phenylmethyl sulfenylfluoride

Sympathoadrenal transmitter systems mature to adult capacity a week or more after birth in response to progressive cholinergic innervation, exposure to growth factors, and hormonal influences from both the hypothalamic-pituitary-adrenal cortical and thyroid hormonal systems (1-6). Although the

Received June 20, 2003; accepted December 8, 2003

Correspondence: Edmund F. La Gamma, M.D., Division of Newborn Medicine, Departments of Pediatrics, Biochemistry, and Molecular Biology, New York Medical College and The Regional Neonatal Center, Westchester Medical Center, Valhalla, NY 10595, U.S.A.; e-mail: edmund_lagamma@nymc.edu

Supported by institutional grants from the Children's Foundation of the Department of Pediatrics.

DOI: 10.1203/01.PDR.0000119365.21770.45 importance of these conventional control mechanisms is well established, the evolutionary significance of other exogenous stimuli can be considered in a broader view of environmentally derived signal-transduction. For example, the delayed period of adrenal transmitter accumulation after birth coincides with the time taken to establish full enteral feedings, colonization of the intestine, and attendant production of SCFA (7). Moreover, in the rat (as well as in humans), this time frame is far longer than the capacity of the chromaffin cell to rapidly induce biosynthesis of either catecholamines or enkephalins, which can occur in a matter of hours (8). Maturational delays occurring up to 2 wk after birth portend the existence of other more gradually acquired regulatory signals. 
In a recent report (9), we hypothesized that gut-derived SCFAs serve a function as "acquired" environmental modulators of the developing sympathoadrenal system. We showed that SB interacted with the classic cholinergic-nicotinic, signaltransduction system and, together, could differentially regulate TH mRNA (the rate-limiting enzyme in catecholamine biosynthesis) and the mRNA for the co-localized neuropeptide transmitter ppEnk (9). Whether other gut-derived or metabolic pathway SCFAs have similar effects as SB and how these influences are mediated at the cellular and molecular level remain largely unknown. Thus, in the present report, we sought to determine whether SCFAs other than SB (or biologically relevant SB derivatives) could modulate classic catecholaminergic or neuropeptide pathways in vitro. If so, this would represent new opportunities to therapeutically enhance neonatal adaptive responses to stress. We also examined which intracellular signal-transduction systems are linked to SB effects and whether long-chain fatty acid binding receptors (PPAR) were involved in the signal-transduction cascade.

\section{METHODS}

Cell culture. The PC12 cells used in the experiments were originally developed by Greene and Tischler (10). They were cultured in Dulbecco's modified Eagle's medium supplemented with $10 \%$ horse serum, $5 \%$ fetal bovine serum, 50 $\mu \mathrm{g} / \mathrm{mL}$ streptomycin, and $50 \mathrm{IU} / \mathrm{mL}$ penicillin as described earlier (9). Cells were treated with the drugs indicated (see figure legends), harvested after $48 \mathrm{~h}$, and processed for further analysis as described below. Each experiment was repeated more than two times, with six individual replicates per experimental group, to permit proper statistical evaluation of the results.

Northern blot analysis. Total RNA was isolated from each individual Petri dish using RNazol (Tel-Test, Inc., Friendswood, TX, U.S.A.), and Northern blot analysis was performed as previously described by us (11). After transfer to Gene Screen Plus membranes, the filters were hybridized consecutively to labeled rat cDNA probe for TH and a probe for $18 \mathrm{~S}$ ribosomal RNA. For detection of ppEnk mRNA, an anti-sense RNA probe was prepared by in vitro transcription of the ppEnk plasmid kindly provided by SL Sabol (12) using MAXIscript SP6 kit (Ambion, Austin, TX, U.S.A.). Filters were washed under proper stringency and exposed for autoradiography, using Kodak BioMax film (Rochester, NY, U.S.A.). The autoradiographs were scanned and the abundance of each mRNA was expressed relative to concomitantly measured $18 \mathrm{~S}$ ribosomal RNA levels. The results are presented as fold induction compared with the corresponding control group on the same Northern blot.

RT-PCR analyses. Total RNA isolated from PC12 cells (1 $\mu \mathrm{g})$ was subjected to RT-PCR analyses using Ready-To-Go RT-PCR beads (Amersham Pharmacia Biotech, Denver, CO, U.S.A.) in a two-step, single-tube reaction, and rat PPAR $\gamma$ gene specific primers [reverse: position 1378 to 1359, 5' GTACGCGGATCAGCATCCCGTC; forward: 5' TGCCAGTACTGCCGTTTCCAC sequence 834-854, Gi:206317 (13)], in a Perkin-Elmer Gene Amplification PCR System 9700. The first (RT) reactions were incubated for $1 \mathrm{~h}$ at $42^{\circ} \mathrm{C}$. After inactivation of the reverse transcriptase $\left(5 \mathrm{~min}\right.$ at $\left.95^{\circ} \mathrm{C}\right), 25$ pmol of both forward and the same reverse primer was added, and the generated cDNA was used directly as a template for polymerization in PCR. After an initial denaturation of $5 \mathrm{~min}$ at $95^{\circ} \mathrm{C}, 30$ cycles of $1 \mathrm{~min}$ at $94^{\circ} \mathrm{C}, 1 \mathrm{~min}$ at $48^{\circ} \mathrm{C}$, and $2 \mathrm{~min}$ at $95^{\circ} \mathrm{C}$ were performed, followed by elongation for $5 \mathrm{~min}$ at $72^{\circ} \mathrm{C}$ and soak file at $4^{\circ} \mathrm{C}$. The resulting PCR products $(5 \mu \mathrm{L}$ from each reaction) were analyzed on $2 \%$ agarose gel using PCR molecular weight markers from Promega (Madison, WI, U.S.A.).

Western blot analyses. PC12 cells were homogenized in 20 mM HEPES, $\mathrm{pH} 7.5 ; 350 \mathrm{mM} \mathrm{NaCl} ; 25 \%$ glycerol; $0.25 \%$ NP-40; $1 \mathrm{mM} \mathrm{Na} \mathrm{VO}_{3} ; 0.25 \mathrm{mM}$ PMSF; $5 \mathrm{mM} \mathrm{MgCl} 2 ; 1$ $\mu \mathrm{g} / \mathrm{mL}$ each of aprotinin, pepstatin, and leupeptin; $1 \mathrm{mM}$ EGTA; and $1 \mathrm{mM}$ DTT. Protein concentration was determined using the Bradford assay. Equal amounts of proteins were separated on $10 \%$ SDS-PAGE, electroblotted onto a nitrocellulose membrane (BioRad, Hercules, CA, U.S.A.), and incubated with an anti-PPAR $\gamma$ antibody (1:500, Santa Cruz Biotech, Santa Cruz, CA, U.S.A.). The immune reaction was visualized by enhanced chemiluminescent substrate from Pierce (Rockford, IL, U.S.A.), using a horseradish peroxidase label and Kodak XAR-5 film, as described by the manufacturer. Mouse heart extract (Santa Cruz Biotech.) was used as a positive control.

Statistical analysis. Data are expressed as mean \pm SEM and normalized to the values in the control, taken as 1 . Differences between the experimental groups from three independent experiments were evaluated by performing ANOVA followed by the Fisher's least significant difference test for experiments with more than two groups. A level of $p \leq 0.05$ was accepted as statistically significant

\section{RESULTS}

Structural requirements for the capacity of different $S C$ FAs and their derivatives to alter neurotransmitter-related gene expression. Using physiologic $\mathrm{pH}$ and blood level concentrations (14) for treatment, we compared the ability of SCFAs with different carbon chain lengths or biologically relevant structural analogs of SB to induce neurotransmitterrelated gene expression in our model system (9). PC12 cells were treated with vehicle or with $1 \mathrm{mM}$ of each SCFA or an SB derivative. Total RNA was isolated from all experimental groups and subjected to Northern blot analysis for the genes of interest as described in "Methods." The results are summarized in Figure 1.

Hybridization of the blots with a radiolabeled TH cDNA probe revealed a 3.5 -fold increase in TH mRNA expression for cells treated with SB when compared with the control $(p<$ 0.05). The five-carbon atom (C5) SCFA, sodium valerate, showed a 1.5- fold increase, whereas sodium caproate (C6) had no statistically significant effect on TH mRNA levels (Fig. 1A). As previously reported by us and by others $(9,15-17)$, SB (C4) treatment of PC12 cells caused a 4-fold increase in ppEnk mRNA expression when compared with the untreated control group $(p<0.05)$. In contrast, SCFAs having shorter carbon 
A.

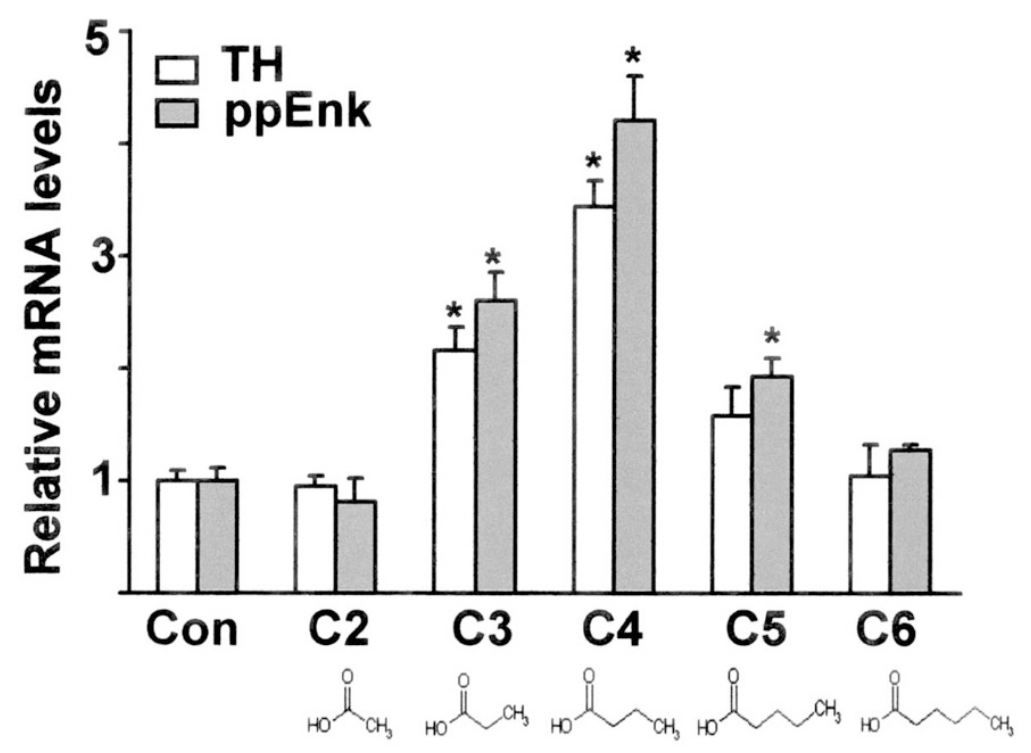

B.

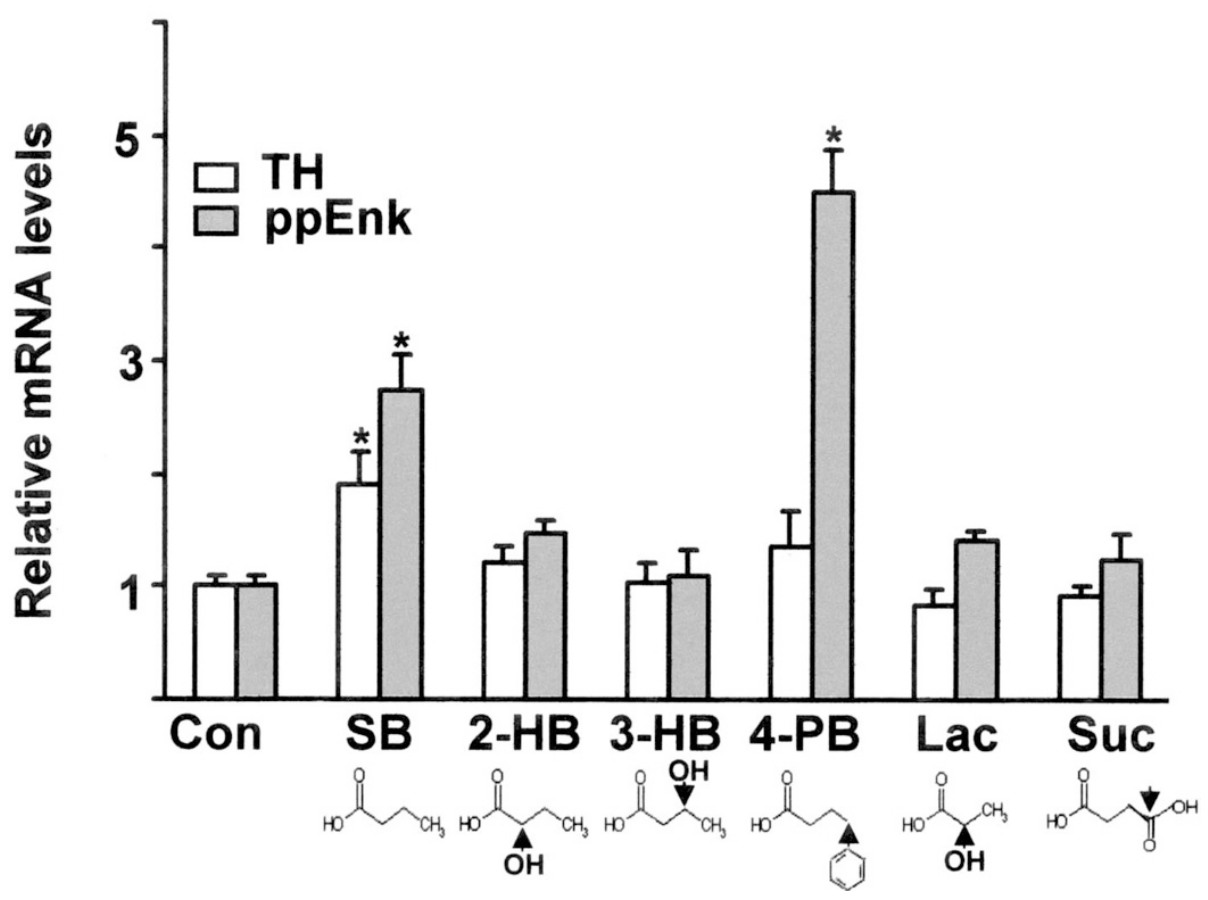

Figure 1. Ability of different SCFAs to regulate neurotransmitter gene expression. $A$, effect of carbon chain length. PC12 cells were treated with $1 \mathrm{mM}$ of each SCFA: acetate (C2), propionate (C3), SB (C4), valerate (C5), and caproate (C6); $B$, structural modifications of SB and propionate: $1 \mathrm{mM}$ of each SB, 2-HB, 3-HB, 4-PB, lactate ( $(\mathrm{Cac})$, and succinate $(\mathrm{Suc})$ were tested. After $48 \mathrm{~h}$, total RNA was isolated and subjected to Northern blot analysis. The changes in the relative mRNA levels are presented as mean \pm SEM values relative to those in untreated cells. $* p<0.05 v$ respective control (Con) group. $n=6$ per group.

chains, such as acetate (C2; the most common SCFA present in either the gut or the bloodstream), did not affect ppEnk or TH mRNA levels (Fig. 1A). Similarly, further increases in carbon chain length ( $\mathrm{C} 5$, valerate, and $\mathrm{C} 6$, caproate) gradually reduced the capacity of SCFAs to induce these transmitter system genes.
We then sought to determine whether different stereochemical modifications of SB would modify its effects on neurotransmitter-related gene expression. PC12 cells were treated with the indicated SCFA at $1 \mathrm{mM}$ final concentration for $48 \mathrm{~h}$, and Northern blot analyses for the genes of interest were performed as described in the "Methods." Although SB and 
4-PB (a lipophilic, pharmacologically stable analog of SB) caused marked increase in the relative steady-state levels of ppEnk mRNA, treatment with either 2-HB or 3-HB failed to result in a statistically significant change in the expression of ppEnk gene (Fig. 1B). The effects of SB and 2-HB or 3-HB were similar for both ppEnk and TH genes. Interestingly, the addition of a hydroxyl group on the second carbon atom of propionate (creating lactate) resulted in loss of the transcription regulatory effect for both ppEnk and TH genes. Similarly, treatment with succinate $(\mathrm{C} 4$, with two carboxylic groups at either end) had no significant effect on neurotransmitter gene expression, suggesting an ethyl moiety $\left(\mathrm{C}_{2} \mathrm{H}_{5}\right)$ in the carbon atom backbone chain is a key to the effect.

In contrast to the common pattern of regulation with naturally occurring SCFAs, a differential pattern of regulation for ppEnk and TH mRNA levels was observed when PC12 cells were treated with a pharmacologic analog of SB, 4-PB, which has been used in humans to treat cancer, hemoglobinopathies, and urea cycle disorders (18). There was a 4.5 -fold increase in ppEnk mRNA expression in PC12 cells treated with 4-PB yet no statistically significant effect on TH mRNA levels compared with control. This suggested that the transcriptional control or mRNA stabilization pathways for TH and ppEnk differ as we have previously noted $(9,19)$.

Rehybridizing the same blots with an $18 \mathrm{~S}$ ribosomal cDNA probe did not show any differences among the experimental groups in any of the above experiments, indicating a genespecific effect of all treatments.

Concentration dependency and chromatin structure. To further define the requirements for the effect of different SCFAs on neurotransmitter-related gene expression, we performed concentration-dependence studies. The capacity of SB and propionate to alter neurotransmitter gene expression was compared at low $(1 \mathrm{mM})$, physiologic concentrations $(7,14)$ and at relatively high $(6 \mathrm{mM})$ doses (Fig. 2). Inasmuch as the effects of these SCFAs in different genetic contexts were closely correlated with the degree of inducible histone hyperacetylation (20-22), increasing concentrations of TSA, a highly specific HDAC inhibitor (23), were also examined. 4-PB was used at doses (millimolar range) similar to the therapeutic plasma concentrations in humans shown to inhibit HDAC in vitro [reviewed in Gore and Carducci (18)]. The results of these treatments are summarized in Figure 2.

As we reported previously (9), both the low $(1 \mathrm{mM})$ and the high $(6 \mathrm{mM})$ doses of SB resulted in a similar magnitude of elevation of ppEnk mRNA levels (Fig. 2A). In contrast, TH mRNA levels were significantly increased at $1 \mathrm{mM}$ but reduced after exposure to $6 \mathrm{mM} \mathrm{SB}$. The higher concentration of propionate had a similar effect on elevating the steady-state levels of ppEnk mRNA (data not shown); however in contrast to $6 \mathrm{mM} \mathrm{SB}$, it did not significantly alter the basal levels of $\mathrm{TH}$ mRNA. Additional evidence for independent regulation of these two neurotransmitter-related genes was provided when increasing concentrations of 4-PB was tested. We found a more than doubling of the rise in the relative ppEnk mRNA levels, whereas the abundance of TH mRNA was essentially unaffected at any doses of the drug studied (Fig. 2B). These data further support the notion that a passive diffusion mechanism is not likely to account for the differential effects of the examined SCFA on neurotransmitter-related gene expression and that it may be related to receptorlike or alternative mechanism.

Interestingly, the specific HDAC inhibitor TSA induced the expression of both genes in a dose-dependent manner (Fig. $2 C$ ). The concentrations of TSA used in these experiments were shown previously by others to result in accumulation of highly acetylated histones (24). This confirmed that HDAC inhibitors can regulate the expression of neurotransmitterrelated genes.

However, our results revealed that although all three SCFAs tested share the ability to inhibit HDAC and, hence, alter chromatin structure, each one had a differential dose- and gene-specific effect on neurotransmitter-related gene expression. This suggests that acetylation of histones or of other preexisting molecules is only one component in a cascade of events initiated by SCFAs resulting in alteration of neurotransmitter gene expression. Other, so far unrecognized, drugspecific and gene-specific pathways may also have an impact on neurotransmitter-related gene expression.

PPAR $\gamma$ as a target for SCFAs. PPAR are involved in many of the transcriptional effects of dietary long-chain fatty acids, fatty acid metabolites, and hypolipidemic and anti-diabetic drugs $(25,26)$. These nuclear receptors are also molecular targets for cell differentiation inducers like phenylacetate and 4-PB (27). Therefore, we hypothesized that members of the PPAR family of receptors may mediate some of the effects of SCFAs on neurotransmitter-related gene expression.

Because PPAR receptors in PC12 cells had never been described and only one recent study reported PPAR expression in the adult rat adrenal (28), Western blot analysis was performed. Total protein extracts from PC12 cells and from the positive-expressing tissue (mouse heart extracts, provided by the vendor) were separated on a $10 \%$ SDS-PAGE, electroblotted, and probed with a PPAR $\gamma$-specific polyclonal antibody. According to the vendor, this antibody is reactive with the two PPAR $\gamma$ isoforms $[\gamma 1$ and $\gamma 2$, reviewed in Rosen and Spiegelman (29)] from mouse, rat, and human; and not crossreactive with PPAR $\alpha$ or PPAR $\beta$ proteins. Typical immunoblot is shown on Figure $3 A$, confirming that detectable levels of $\operatorname{PPAR} \gamma$ are expressed in PC12 cells.

In addition, when total RNA from PC12 cells was subjected to RT-PCR analysis, a DNA fragment of predicted size (544 bp) was obtained (Fig. 3B, lanes 2 and 3). As a control for genomic DNA contamination, the reverse transcriptase was heat-inactivated in the first step (lane 4), and no amplification fragment was observed in this reaction. Thus, both Western blot and RT-PCR analyses indicated detectable levels of expression of PPAR $\gamma$ in PC12 cells.

PPARs function as ligand-activated transcription factors, which heterodimerize with the RXR. Transcriptional activation of target genes occurs after the activated PPAR-RXR complex binds to a response element in the $5^{\prime}$ region of the target gene. To test whether ppEnk and TH genes are potential targets for transcriptional regulation by PPAR $\gamma$, we performed a computer-based sequence homology search of the published rat TH and ppEnk promoter sequences. The Genomatix MatInspector search (30) for PPAR $\gamma$ binding sites (direct repeat of an 


\section{A.}

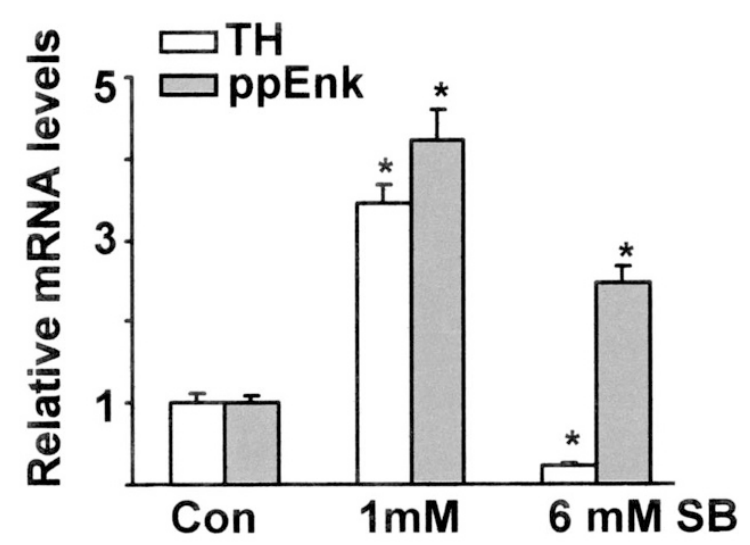

B.

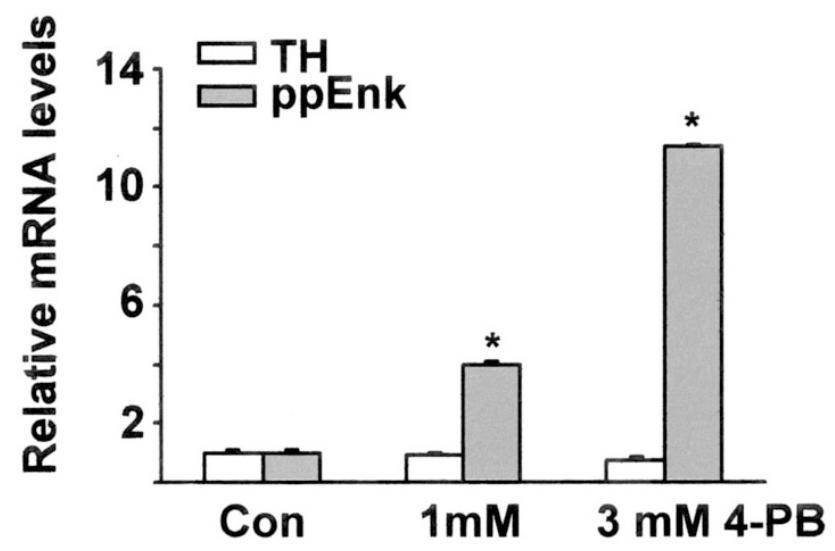

C.

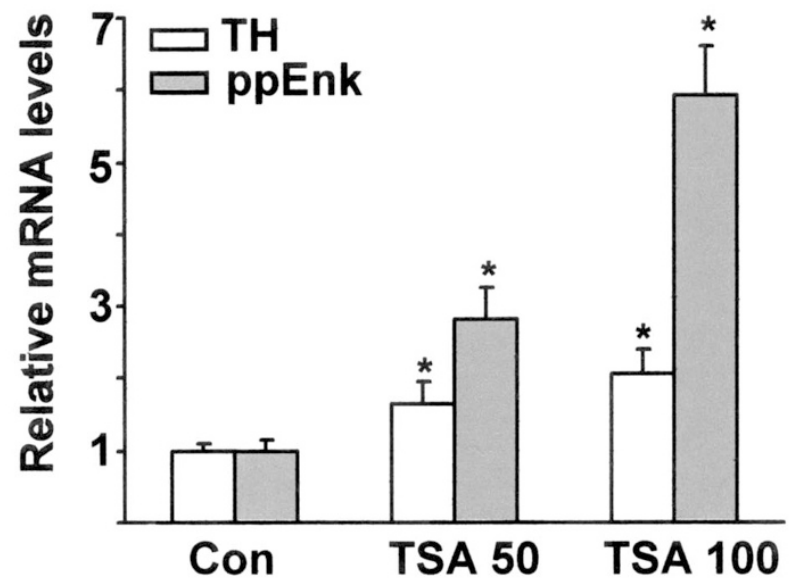

Figure 2. Dose-dependent changes in the response. Increasing concentrations of the tested drugs ( $A$, SB; $B, 4-\mathrm{PB} ; C$, TSA) or vehicle were added to $\mathrm{PC} 12$ cells. After $48 \mathrm{~h}$, total RNA was isolated and subjected to Northern blot analyses. The data obtained for relative mRNA levels are presented as mean \pm SEM values relative to those in control (Con) cells. ${ }^{*} p<0.05$ vs respective Con group. $n=6$ per group.
A.

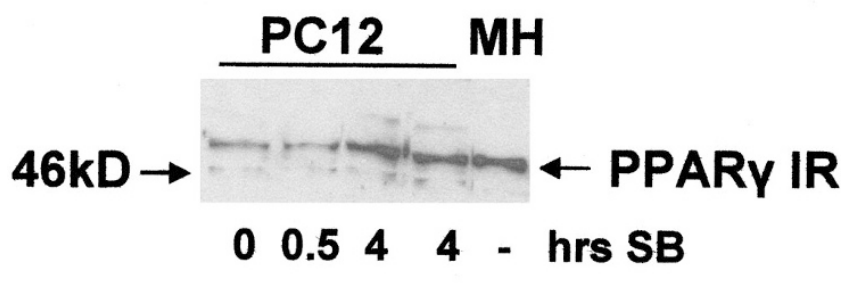

B.

bp:

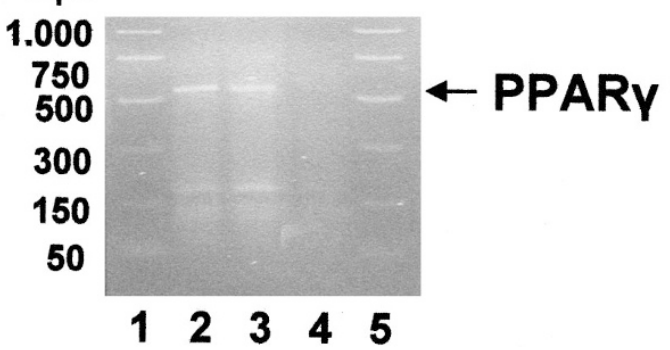

Figure 3. Identification of PPAR $\gamma$-immunoreactive $(I R)$ protein and PPAR $\gamma$ mRNA in PC12 cells. $A$, total homogenates from PC12 cells and from mouse heart extract $(M H)$ were subjected to Western blot analyses using an antibody specific for PPAR $\gamma$. The mobility of the marker proteins and mouse PPAR $\gamma$-IR protein is indicated. B, agarose gel electrophoresis: markers (lanes 1, 5); RT-PCR products from total RNA isolated from PC12 cells (lanes 2, 3); and control for DNA contamination (lane 4). The arrow indicates the PPAR $\gamma$ fragment of expected size.

AGGNCA half-site separated by a 1-bp spacer (29) revealed at least one potential PPRE motif in the upstream region of rat ppEnk gene (position -393 to -374 upstream of the transcription start site (31). Whether this element is able to bind specifically PPAR $\gamma$-RXR heterodimers remains to be elucidated. No such homologies were found in the rat TH promoter, consistent with the lack of induction of TH mRNA levels by PB (Figs. $1 A$ and $2 B$ ).

To test the hypothesis that PPAR $\gamma$ may mediate the effects of SCFAs, we examined whether diclofenac will antagonize the actions of SB in PC12 cells. Diclofenac is a widely used analgesic, binds to PPAR $\gamma$ at clinically relevant concentrations, and also antagonizes PPAR $\gamma$ transactivation by rosiglitazone in a receptor-mediated manner in 3T3-L1 preadipocyte cells (32). Treatment of PC12 cells with diclofenac alone did not cause a statistically significant change in the relative ppEnk mRNA levels (Fig. 4A). However when cells were grown in the presence of both 4-PB and diclofenac, we observed a 50\% reduction of the rise of ppEnk mRNA levels triggered by 4-PB alone. In contrast, diclofenac was found to have only marginal (not statistically significant) effects on SB-induced ppEnk gene expression (Fig. 4B). Similar results were obtained for $\mathrm{TH}$ (data not shown). Thus, in contrast to the drug 4-PB, signaling through PPAR $\gamma$ nuclear receptors does not appear to be the 

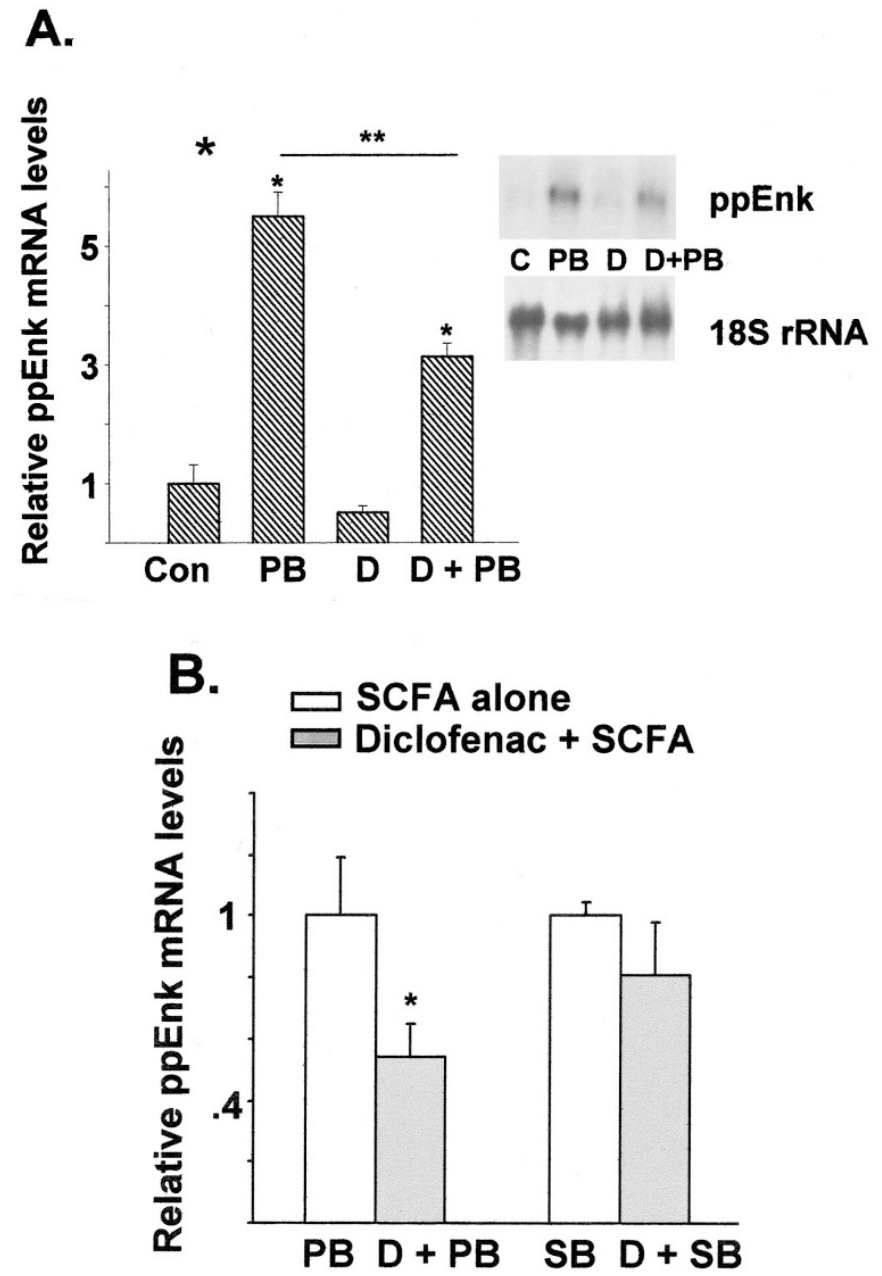

Figure 4. Effect of PPAR $\gamma$ receptor antagonist diclofenac $(D)$. A, diclofenac antagonizes PB-induced ppEnk gene expression. The effect of $25 \mu \mathrm{M} \mathrm{D}$ on PB-induced ppEnk mRNA levels was compared with that of $1 \mathrm{mM}$ PB alone. The inset shows a typical Northern blot. Error bars indicate SEM. ${ }^{*} p<0.05$ $v s$ corresponding controls $(C ; C o n), n=6$ per group. $B$, comparison of the effect of D on PB- and SB-induced ppEnk gene expression.

major pathway triggered by gut-derived SB to alter transcription of these neurotransmitter-related genes.

Requirements for an intact PKA signaling pathway. Recently several SCFA were identified as specific agonists for orphan G-protein-coupled receptors GPR41 and GPR43 (33). A large number of hormones, neurotransmitters, and other signaling substances that bind to G-protein-coupled receptors have their signals converge at one sole second messenger, cAMP. On the basis of these data, we examined whether activation of the PKA-cAMP second messenger system is essential for the induction of neurotransmitter-related gene expression by SCFA in our model system.

Genetically engineered PKA-deficient PC12 cells (cell line A123.7) were used in these experiments (34). Treatment of A123.7 cells with SB failed to alter the steady-state levels of mRNA for TH and ppEnk genes (Fig. 5). Forskolin, well known for its ability to activate adenylate cyclase, resulting in increased cAMP levels, activation of PKA pathway, and stimulation of cAMP-responsive genes [including TH and ppEnk $(2,3,5)]$ in wild-type $\mathrm{PC} 12$ cells, was used as a positive

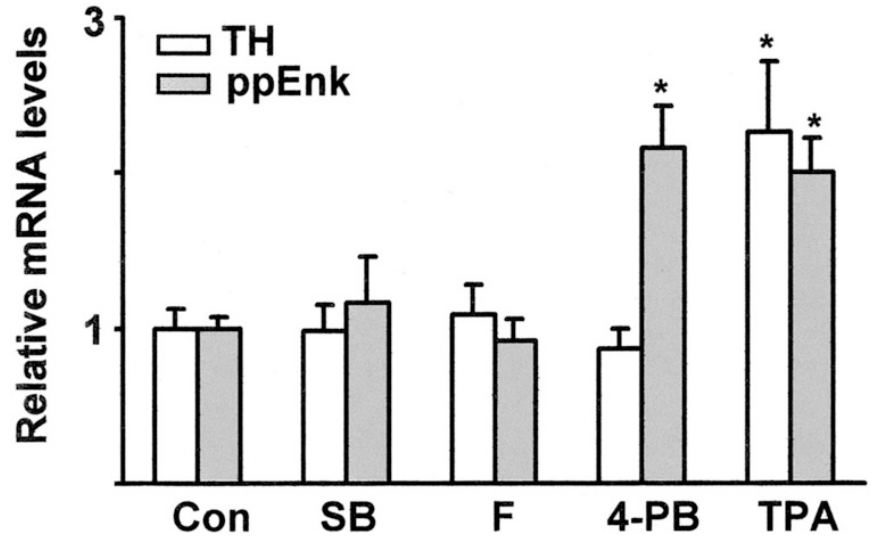

Figure 5. Different requirements for cAMP signaling pathway: The effects of vehicle (Con) or $1 \mathrm{mM} \mathrm{SB}, 20 \mu \mathrm{M}$ forskolin $(F), 1 \mathrm{mM} 4-\mathrm{PB}$, and $2 \mu \mathrm{M}$ 12-O-tetradecanoylphorbol 13-acetate (TPA) were examined in PKA-deficient PC12 cells [A123.7 (34)]. The changes in the relative ppEnk and TH mRNA levels were determined by Northern blot analysis and are presented as mean \pm SEM values relative to those in vehicle-treated cells. ${ }^{*} p<0.05 v s$ respective Con group.

control in these experiments. Addition of forskolin to A123.7 cells did not induce both TH and ppEnk mRNA levels. However, ppEnk mRNA levels were increased in A123.7 cells in response to 4-PB treatments. In contrast, 12-O-tetradecanoylphorbol 13-acetate, a phorbol ester that activates the protein kinase $\mathrm{C}$ pathway, still resulted in an increase in both $\mathrm{TH}$ and ppEnk mRNA levels, indicating that the cells are viable and responsive to treatments, stimulating a different pathway.

Thus, these data indicate that SCFAs and structural analogs of SB display different requirements for the cAMP-PKA second messenger system for their effects on neurotransmitterrelated gene expression: the endogenous physiologic agent (SB) is linked to activation of PKA pathway, whereas the pharmacologic congener (4-PB) is not.

\section{DISCUSSION}

In the present report, we determined that a variety of biologically relevant, gut-derived SCFAs affect neurotransmitterrelated gene expression in PC12 cells at physiologic blood concentrations. Our results were also consistent with the existence of steric-structural requirements for the stimulatory effect of these SCFAs, suggesting a receptor-like mechanism exists as well as regulatory links to HDAC, cAMP-dependent intracellular mechanisms but not to PPAR $\gamma$ fatty acid receptors.

Propionate (C3) as well as SB (C4) resulted in a statistically significant increase in ppEnk and TH mRNA levels when compared with vehicle-treated controls (Fig. 1, $p<0.05$ for both). In contrast, SCFAs having shorter carbon chains, like acetate $(\mathrm{C} 2$; the most common SCFA present in either the gut or the bloodstream), did not affect ppEnk or TH mRNA levels (Fig. 1). Increases in carbon chain length (C5, valerate, and C6, caproate) gradually reduced the capacity of SCFAs to induce these transmitter system genes. This functional hierarchy is similar to effects on colon carcinoma cells, in which SB is the most potent SCFA in inducing cellular growth arrest, differentiation, and apoptosis, followed by propionate and valerate 
(20). G-protein-coupled receptor activation of polymorphonuclear leukocytes follows faithfully to this chain-length cascade as well (35).

On further analysis, we defined additional structural requirements of SCFAs. Specifically, creating ketone bodies (markers of hypoglycemic ketosis) by hydroxylation of the ethyl moiety of the parent SB molecule (2-HB or 3-HB) efficiently eliminated the effects on the neurotransmitter-related mRNA levels (Fig. $1 B$ ). Moreover, succinate ( $\gamma$-carboxylbutyrate) or lactate ( $\alpha$-OH-propionate), both naturally occurring metabolites of the oxidative degradation of glucose via the Krebs cycle or carboxylic acid cycle, also had no effect on altering catecholamine or enkephalin mRNA levels. Therefore, it appears that only gut-derived SCFAs (i.e. propionate and SB) with a conserved $\mathrm{C}_{2} \mathrm{H}_{5}$ - $\mathrm{R}$ (ethyl) moiety can induce $\mathrm{TH}$ and ppEnk transmitterrelated genes.

These actions of SB are relevant and likely to occur in vivo because rats fed a high-fiber diet can have high luminal SB levels [up to $40 \mathrm{mM}$, see Fitch and Fleming (36)], already shown to be associated with histone hyperacetylation and growth inhibition of colonic epithelial cells (37). Taken together, our results support the interpretation that stereospecific requirements exist for the capacity of SCFAs and their structural analogs to modulate neurotransmitter-related gene expression. This evokes an intriguing argument for the existence of a receptor-mediated SCFA signal-transduction pathway(s) that may also be important in facilitating movement of fatty acids across cell membranes or into the nucleus.

Given the common requirement for an intact PKA intracellular signaling pathway for the stimulatory effects of SCFAs on neurotransmitter gene expression reported here, it is attractive to speculate that G-protein-linked receptors, coupled to the cAMP-PKA cascade, are potential candidates mediating SCFA responses in PC12 cells. In support of this interpretation is the activation of orphan G-protein-coupled receptors GPR41 and GPR43 by SCFAs propionate and SB, respectively $(33,35)$. Because the pharmacology of GPR43 matched the effects of SCFA on neutrophils, the authors speculated that such receptors may be involved in the development of inflammatory bowel disease, a finding that may also have relevance to the origins of neonatal bowel diseases like necrotizing enterocolitis (38).

In addition to the G-protein-coupled receptor family, we identified four independent lines of evidence to support a functional relationship between PPAR $\gamma$ and transmitter-related gene regulation by 4-PB: 1) PPAR $\gamma$ mRNA and protein is expressed in PC12 cells at detectable levels; 2) diclofenac, a nonsteroidal antiinflammatory drug and a known PPAR $\gamma$ blocking agent, antagonizes the effect of 4-PB on neurotransmitter gene expression; 3) a Genomatix MatInspector search for PPAR $\gamma$ binding sites revealed at least one potential PPRE motif in the upstream region of rat ppEnk gene; and 4) no putative $\mathrm{PPAR} \gamma$ promoter elements were found in the $\mathrm{TH}$ gene and no effect of 4-PB on TH mRNA was observed. The identification of PPAR $\gamma$ in nonadipose tissues suggests novel functions for this receptor family that are distinct from its well-characterized long-chain fatty acid metabolic regulatory activity $(39,40)$. One of them could be a potential role of
PPAR signaling in the development of the peripheral nervous system, its regulation and functions mediated via catecholamine or opiate peptide transmitter systems. Indeed, dietary C20 fatty acids have been reported to affect catecholamine synthesis in the CNS (41).

\section{CONCLUSIONS}

In conclusion, although the SCFAs found to affect neurotransmitter-related gene expression all share the ability to inhibit HDAC $(18,20-22)$, their final impact at the level of gene expression appears to be determined by activation of gene-specific signal-transduction pathways and the relative importance of pharmacologic properties of the treatments, including drug type and dose. Furthermore, our data implicate both G-protein orphan and PPAR $\gamma$ receptors as being involved in the independent regulation of catecholaminergic and opioid pathways by SCFAs and by related drugs like 4-PB. Taken together, our findings link disparate physiologic functions into a new view of interactive systems in which dietary intake and lipid metabolism may also be influenced by environmental signals governing sympathoadrenal stress-adaptation and cardiovascular pathophysiology via catecholaminergic pathways (42).

We speculate that 1) circulating levels of SCFAs may influence sympathoadrenal transmitter biosynthesis and hence whole animal stress-adaptive responsiveness after birth, and 2) the adverse effects of antibiotics on delayed acquisition of postnatal gut flora may affect this apparent evolutionary advantage of gut colonization. Further work will be necessary to test these hypotheses in living animals.

Acknowledgments. The authors thank Ning Yuan (Regeneron Inc.) for the excellent technical assistance in some of the laboratory experiments.

\section{REFERENCES}

1. Slotkin TA 1985 Development of the Sympathoadrenal Axis. Humana Press, New York, pp 69-96

2. Sabban EL 1997 Control of tyrosine hydroxylase gene expression in chromaffin and PC12 cells. Semin Cell Dev Biol 8:101-111

3. Weisinger G 1995 The transcriptional regulation of the preproenkephalin gene. Biochem J 307:617-629

4. DeCristofaro JD, LaGamma EF 1994 Neonatal stress: effects of hypoglycemia and hypoxia on adrenal tyrosine hydroxylase gene expression. Pediatr Res 36:719-723

5. Kumer SC, Vrana KE 1996 Intricate regulation of tyrosine hydroxylase activity and gene expression. J Neurochem 67:443-462

6. Hamill RW, Gamma EFL 1992 Autonomic nervous system development. In: Bannister SR (ed) Autonomic Failure: A Textbook of Clinical Disorders of the Autonomic Nervous System. Oxford University Press, New York, pp 15-35

7. Topping DL, Clifton PM 2001 Short-chain fatty acids and human colonic function: roles of resistant starch and nonstarch polysaccharides. Physiol Rev 81:1031-1064

8. Lau C, Ross LL, Whitmore WL, Slotkin TA 1987 Regulation of adrenal chromaffin cell development by the central monoaminergic system: differential control of norepinephrine and epinephrine levels and secretory responses. Neuroscience 22:10671075

9. Nankova BB, Chua J, Mishra R, Kobasiuk CD, La Gamma EF 2003 Nicotinic induction of preproenkephalin and tyrosine hydroxylase gene expression in butyratedifferentiated rat PC12 cells: a model for adaptation to gut-derived environmental signals. Pediatr Res 53:1-6

10. Greene LA, Tischler AS 1976 Establishment of a noradrenergic clonal line of rat adrenal pheochromocytoma cells which respond to nerve growth factor. Proc Nat Acad Sci USA 73:2424-2428

11. Nankova B, Kvetnansky R, McMahon A, Viskupic E, Hiremagalur B, Frankle G, Fukuhara K, Kopin IJ, Sabban EL 1994 Induction of tyrosine hydroxylase gene expression by a nonneuronal nonpituitary-mediated mechanism in immobilization stress. Proc Natl Acad Sci USA 91:5937-5941 
12. Yoshikawa K, Williams C, Sabol SL 1984 Rat brain preproenkephalin mRNA: cDNA cloning, primary structure, and distribution in the central nervous system. J Biol Chem 259:14301-14308

13. Gottlicher M, Widmark E, Li Q, Gustafsson JA 1992 Fatty acids activate a chimera of the clofibric acid-activated receptor and the glucocorticoid receptor. Proc Nat Acad Sci USA 89:4653-4657

14. Storer G, Trimble R, Illman RJ, Snoswell A, Topping D 1983 Effects of dietary oat bran and diabetes on plasma and caecal volatile fatty acids in the rat. Nutr Res 3:519-526

15. Byrd JC, Alho H 1987 Differentiation of PC12 pheochromocytoma cells by sodium butyrate. Brain Res 428:151-155

16. Lewis EJ, Tank AW, Weiner N, Chikaraishi DM 1983 Regulation of tyrosine hydroxylase mRNA by glucocorticoid and cyclic AMP in a rat pheochromocytoma cell line: isolation of a cDNA clone for tyrosine hydroxylase mRNA. J Biol Chem 258:14632-14637

17. Ebert SN, Lindley SE, Bengoechea TG, Bain D, Wong DL 1997 Adrenergic differentiation potential in PC12 cells: influence of sodium butyrate and dexamethasone. Brain Res Mol Brain Res 47:24-30

18. Gore SD, Carducci MA 2000 Modifying histones to tame cancer: clinical development of sodium phenylbutyrate and other histone deacetylase inhibitors. Expert Opin Investig Drugs 9:2923-2934

19. LaGamma EF, Adler JE, Black IB 1984 Impulse activity differentially regulates [Leu]enkephalin and catecholamine characters in the adrenal medulla. Science 224:1102-1104

20. Hinnebusch BF, Meng S, Wu JT, Archer SY, Hodin RA 2002 The effects of short-chain fatty acids on human colon cancer cell phenotype are associated with histone hyperacetylation. J Nutr 132:1012-1017

21. Huang N, Katz JP, Martin DR, Wu GD 1997 Inhibition of IL-8 gene expression in Caco-2 cells by compounds which induce histone hyperacetylation. Cytokine 9:27-36

22. Fusunyan RD, Quinn JJ, Fujimoto M, MacDermott RP, Sanderson IR 1999 Butyrate switches the pattern of chemokine secretion by intestinal epithelial cells through histone acetylation. Mol Med 5:631-640

23. Yoshida M, Kijima M, Akita M, Beppu T 1990 Potent and specific inhibition of mammalian histone deacetylase both in vivo and in vitro by trichostatin A. J Biol Chem 265:17174-17179

24. Futamura M, Monden Y, Okabe T, Fujita-Yoshigaki J, Yokoyama S, Nishimura S 1995 Trichostatin A inhibits both ras-induced neurite outgrowth of PC12 cells and morphological transformation of NIH3T3 cells. Oncogene 10:1119-1123

25. Grimaldi PA 2001 Fatty acid regulation of gene expression. Curr Opin Clin Nutr Metab Care 4:433-437

26. Chawla A, Repa JJ, Evans RM, Mangelsdorf DJ 2001 Nuclear receptors and lipid physiology: opening the X-files. Science 294:1866-1870

27. Pineau T, Hudgins WR, Liu L, Chen LC, Sher T, Gonzalez FJ, Samid D 1996 Activation of a human peroxisome proliferator-activated receptor by the antitumor agent phenylacetate and its analogs. Biochem Pharmacol 52:659-667

28. Escher P, Braissant O, Basu-Modak S, Michalik L, Wahli W, Desvergne B 2001 Ra PPARs: quantitative analysis in adult rat tissues and regulation in fasting and refeeding. Endocrinology 142:4195-4202
29. Rosen ED, Spiegelman BM 2001 PPARgamma: a nuclear regulator of metabolism, differentiation, and cell growth. J Biol Chem 276:37731-37734

30. Quandt K, Frech K, Karas H, Wingender E, Werner T 1995 MatInd and MatInspector: new fast and versatile tools for detection of consensus matches in nucleotide sequence data. Nucleic Acids Res 23:4878-4884

31. Durkin RC, Weisinger G, Holloway MP, La Gamma EF 1992 Primary sequence of -1436 to +53 bp of the rat preproenkephalin gene putative Z-DNA and regulatory motifs. Biochim Biophys Acta 1131:349-351

32. Adamson DJ, Frew D, Tatoud R, Wolf CR, Palmer CN 2002 Diclofenac antagonizes peroxisome proliferator-activated receptor-gamma signaling. Mol Pharmacol 61:7-12

33. Brown AJ, Goldsworthy SM, Barnes AA, Eilert MM, Tcheang L, Daniels D, Muir AI, Wigglesworth MJ, Kinghorn I, Fraser NJ, Pike NB, Strum JC, Steplewski KM, Murdock PR, Holder JC, Marshall FH, Szekeres PG, Wilson S, Ignar DM, Foord SM, Wise A, Dowell SJ 2003 The orphan G protein-coupled receptors GPR41 and GPR43 are activated by propionate and other short chain carboxylic acids. J Biol Chem 278:11312-11319

34. Ginty DD, Glowacka D, Bader DS, Hidaka H, Wagner JA 1991 Induction of immediate early genes by $\mathrm{Ca}^{2+}$ influx requires cAMP-dependent protein kinase in PC12 cells. J Biol Chem 266:17454-17458

35. Le Poul E, Loison C, Struyf S, Springael JY, Lannoy V, Decobecq ME, Brezillon S, Dupriez V, Vassart G, Van Damme J, Parmentier M, Detheux M 2003 Functional characterization of human receptors for short chain fatty acids and their role in polymorphonuclear cells activation. J Biol Chem 278:25481-25489

36. Fitch MD, Fleming SE 1999 Metabolism of short-chain fatty acids by rat colonic mucosa in vivo. Am J Physiol 277:G31-G40

37. Boffa LC, Lupton JR, Mariani MR, Ceppi M, Newmark HL, Scalmati A, Lipkin M 1992 Modulation of colonic epithelial cell proliferation, histone acetylation, and luminal short chain fatty acids by variation of dietary fiber (wheat bran) in rats. Cancer Res 52:5906-5912

38. Nafday SM, Green RS, Chauvin SN, Holzman IR, Magid MS, Lin J 2002 Vitamin A supplementation ameliorates butyric acid-induced intestinal mucosal injury in newborn rats. J Perinat Med 30:121-127

39. Braissant O, Foufelle F, Scotto C, Dauca M, Wahli W 1996 Differential expression of peroxisome proliferator-activated receptors (PPARs): tissue distribution of PPARalpha, - beta, and -gamma in the adult rat. Endocrinology 137:354-366

40. Park KS, Ciaraldi TP, Abrams-Carter L, Mudaliar S, Nikoulina SE, Henry RR 1997 PPAR-gamma gene expression is elevated in skeletal muscle of obese and type II diabetic subjects. Diabetes 46:1230-1234

41. de la Presa Owens S, Innis SM 1999 Docosahexaenoic and arachidonic acid prevent a decrease in dopaminergic and serotoninergic neurotransmitters in frontal cortex caused by a linoleic and alpha-linolenic acid deficient diet in formula-fed piglets. $\mathrm{J}$ Nutr 129:2088-2093

42. LaGamma EF, Chua J, Kobasiuk CD, Sabban EL, Evinger MJ 2000 Synergistic interaction between bacterial fermentation of dietary carbohydrate and postnatal maturation of the autonomic nervous system (ANS): a hypothesis on evolution of two animal kingdoms. Pediatr Res 47:409A 